Luís Roberto Gonçalves dos Santos ${ }^{1}$

Mariana Pires Menezes ${ }^{1}$

Silvia Mayumi Obana Gradvohl ${ }^{1}$

${ }^{1}$ Departamento de Psicologia, Universidade São Francisco. R. Alexandre Rodrigues Barbosa 45. 13.251-900 Itatiba SP. silviagradvohl@gmail.com

\title{
Conhecimento, envolvimento e sentimentos de concluintes dos cursos de medicina, enfermagem e psicologia sobre ortotanásia
}

\author{
The knowledge, involvement and feelings of students graduating \\ in medicine, nursing and psychology about orthothanasia
}

\begin{abstract}
Orthothanasia involves the suspension of medical procedures for terminal phase patients, which leads to a natural death, relieving the symptoms that cause suffering. In this process, professionals such as physicians, nurses and psychologists, interact with patients and their families. Therefore, it is desirable that during undergraduate studies these professionals should take subjects geared to handle this aspect. The scope of this qualitative study was to evaluate the awareness with respect to orthothanasia of undergraduates in medicine, nursing and psychology courses in a university. Trigger questions in semi-structured interviews were conducted with 22 students. The interviews were recorded and transcribed for content analysis and core identification themes. Three categories were identified: knowledge about orthothanasia; who should be involved in this process; and feelings experienced when facing death. The data revealed that students have scant knowledge about the subject, consider the family involvement in the orthothanasia decision to be important and they do not feel prepared to deal with death situations. The conclusion points to the need to change the focus on the end-of-life issue in the undergraduate courses in the area of health care in order to prepare the future professional adequately.
\end{abstract}

Key words Orthothanasia, Health professionals, Death
Resumo Na ortotanásia ocorre a suspensão dos procedimentos médicos na fase terminal do paciente para que ocorra a morte natural, com o alívio dos sintomas que levam ao sofrimento. Neste processo, profissionais como médicos, enfermeiros e psicólogos, interagem com o paciente e seus familiares. Por isso, édesejável que desde a graduação estes profissionais tenham em suas formações disciplinas voltadas para esta demanda. $O$ objetivo desta pesquisa qualitativa foi avaliar o conhecimento sobre ortotanásia dos concluintes dos cursos de medicina, enfermagem e psicologia de uma universidade. Por meio de questões disparadoras foi realizada entrevista semiestruturada com 22 alunos. As entrevistas foram gravadas e transcritas para análise de conteúdo e identificação de categorias temáticas. Foram identificadas três categorias: conhecimento sobre a ortotanásia, quem deveria se envolver com este processo e sentimentos vivenciados frente à morte. Os dados mostraram que os estudantes possuem um baixo conhecimento sobre o tema, consideram importante o envolvimento dos familiares na decisão da ortotanásia, e não se sentem preparados para o enfrentamento da morte. Conclui-se que há a necessidade de mudanças sobre o enfoque dado ao tema terminalidade nos cursos de graduação da área da saúde, visando preparar melhor os futuros profissionais.

Palavras-chave Ortotanásia, Profissionais de saúde, Morte 


\section{Introdução}

Desde 13 de Abril de 2010, o Conselho Federal de Medicina (CFM) incluiu no Novo Código de Ética Médica a prática da ortotanásia, legalizada pela Lei 6715/09, que legitima a possibilidade do paciente com doença grave e irreversível ou de seus familiares solicitarem a suspensão dos procedimentos médicos para que ocorra a morte natural uma vez que não há possibilidades terapêuticas de cura ${ }^{1}$.

$\mathrm{Na}$ prática da ortotanásia, o paciente continua recebendo os cuidados básicos e paliativos, o que se interrompe é o uso da tecnologia ou procedimentos fúteis como forma de prolongar a morte dolorosa, ou seja, a distanásia. Tampouco ocorre na ortotanásia o auxílio para acelerar o processo da morte como na eutanásia. A ortotanásia compreende a morte com dignidade, na qual o paciente, assim como pôde escolher como viveria, pode também escolher como morrer².

Embora a prática seja oficialmente legaliza$\mathrm{da}$, as pessoas envolvidas em situações de terminalidade da vida, ou seja, o próprio paciente, a família e a equipe médica, não optam de maneira tranquila pela ortotanásia ${ }^{3}$. Isto ocorre porque embora a morte faça parte do desenvolvimento humano, o homem moderno, principalmente o ocidental, tenta vencê-la a todo custo, por considerá-la como sinônimo de impotência, fracasso e vergonha. Desta forma, a opção pela ortotanásia, pela morte natural, sem interferência da ciência, pode gerar sentimentos de medo, culpa, dúvida, angústia e incerteza ${ }^{4}$.

Frente ao final da vida, os cuidados paliativos surgem para proporcionar ao paciente uma morte digna e sem dor, centrando as intervenções no doente e não na doença e contrapondo o uso continuado de qualquer tecnologia para a manutenção da vida a qualquer preço ${ }^{5}$. Embora venha assumindo importância crescente no mundo, os cuidados paliativos ainda são um assunto negligenciado na maioria dos países. No Brasil, a cultura paternalista privilegia uma relação com o paciente terminal fundamentada na omissão de informação e na mentira, impedindo-o de fazer escolhas livres sobre os cuidados que gostaria de receber no final de sua vida ${ }^{6}$. Reconhecer a autonomia do paciente e atender as suas expectativas e necessidades são aspectos fundamentais neste momento. Pesquisas nacionais realizadas na última década mostram a importância do preparo e capacitação do profissional da saúde para o enfrentamento da terminalidade ${ }^{7}$.

Em situações de hospitalizações, diferentes profissionais interagem com o processo da mor- te e do morrer. Entre os diversos profissionais da saúde que necessitam lidar com este assunto, encontram-se médicos, enfermeiros e psicólogos nos quais a vivência da morte de um paciente faz com que estes tenham que lidar com suas próprias emoções, colocando-os frente a suas próprias finitudes gerando angústias. Desta maneira, há a necessidade de se estudar tais profissionais e suas dificuldades em falar sobre a morte, pois somente assim será possível identificar lacunas de conhecimentos e meios para se formar um profissional capaz de dar uma atenção humanizada para o paciente terminal ${ }^{8}$. Para isso, entretanto, é preciso se considerar que estes profissionais, assim como as outras pessoas, estão inseridos em um contexto sócio-histórico de negação da morte e também são influenciados pelos aspectos teóricos e técnicos decorrentes de suas formações profissionais, os quais deveriam contribuir para a formação ética e humanizada do cuidar'. Dentro desse contexto, é importante que tais profissionais tenham tido conhecimento teórico reflexivo a respeito da ortotanásia durante o processo de sua formação profissional.

O objetivo deste artigo é identificar o conhecimento sobre a ortotanásia dos concluintes dos cursos de medicina, enfermagem e psicologia de uma universidade do interior do estado de São Paulo.

\section{Metodologia}

A presente pesquisa qualitativa foi aprovada pelo Comitê de Ética em Pesquisa da Universidade São Francisco e foi realizada em uma universidade do interior do estado de São Paulo com alunos concluintes dos cursos de medicina, enfermagem e psicologia. A seleção da amostra foi intencional e o número de participantes foi definido através do critério de saturação. Por meio deste procedimento, é suspensa a inclusão de novos participantes, a partir do momento em que se chega à compreensão de que não haveria necessidade de incluir novos sujeitos, pois o material coletado seria suficiente para alcançar os objetivos do projeto ${ }^{10}$. No total 22 alunos participaram da pesquisa, 6 do curso de medicina, 10 de enfermagem e 6 de psicologia.

Durante 3 meses, no período de outubro a dezembro de 2012, os alunos foram contatados pessoalmente pelos pesquisadores dentro dos campi da universidade, informados a respeito dos objetivos da pesquisa e consultados acerca da participação na mesma. A entrevista foi feita individualmente e em local que garantiu a privaci- 
dade do trabalho, tais como salas de aula, biblioteca e sala privativa do hospital universitário. Todos os alunos participantes assinaram o Termo de Consentimento Livre e Esclarecido. Os dados da pesquisa foram obtidos por meio da realização de entrevistas semiestruturadas com os alunos participantes.

As entrevistas foram gravadas e para a realização das perguntas foi utilizado um roteiro com questões disparadoras, visando motivar o discente a discorrer livremente sobre o tema da pesquisa. As questões disparadoras foram: $O$ que você sabre sobre a ortotanásia?, Lembra-se de o tema ter sido discutido em sua graduação?, Quem deve ser envolvido na decisão da ortotanásia?, Como futuro profissional da saúde, como você vê o seu papel no processo da ortotanásia?, Você já vivenciou algum caso de final de vida e/ou ortotanásia?, Quais foram as suas dificuldades na vivência da terminalidade e/ou ortotanásia?.

Após a realização das entrevistas, todos os conteúdos foram transcritos e submetidos à análise de conteúdo ${ }^{11,12}$. Seguindo esta metodologia, todo o material foi lido diversas vezes para absorção global das principais ideias dos discursos coletados e seus conceitos gerais. Em seguida, foram selecionadas unidades de análise, tais como sentenças e frases cujos significados se repetiam de maneira consistente nas diversas entrevistas coletadas. Desta maneira identificaram-se categorias temáticas ${ }^{13}$ capazes de agregar sob um mesmo tema as diversas informações existentes nas entrevistas. Tais categorias foram validadas pela interação dos pesquisadores sob a supervisão de um orientador sênior.

\section{Resultados}

A amostra foi composta por 22 alunos, sendo constituída por 6 do curso de medicina $(\mathrm{M})$, sendo 4 do sexo masculino e idade média de 25 anos; já entre os 10 alunos de enfermagem (E), 8 foram do sexo feminino e a média de idade foi de 28 anos; por fim, entre os 6 alunos participantes do curso de psicologia (P), 5 eram do sexo feminino e possuíam idade média de 32 anos.

Após a leitura exaustiva das transcrições para a realização da análise do conteúdo, foram identificadas 3 categorias: conhecimento sobre a ortotanásia, quem deveria se envolver no processo da ortotanásia e, por fim, sentimentos vivenciados frente à temática morte.

$\mathrm{Na}$ primeira categoria, os resultados evidenciaram que, apesar de todos os participantes te- rem o tema ortotanásia abordado durante a graduação, poucos conseguiram definir do que se tratava.

... falam pouco, mas bem por cima. Poderia ter um enfoque maior. Ortotanásia eu não sei exatamente... uma maneira de você garantir uma morte sem muito sofrimento, tentar manter uma integridade na morte (M5)

eu lembro que foi discutido na graduação, mas classificar o que vem a ser, eu não sei dizer (E8)

Foi, foi discutida [ortotanásia]. Até nessas aulas agora, nesses últimos semestres [...] eu sempre confundo: distanásia, eutanásia, ortotanásia. Agora eu não sei diferenciar para você qual que é, entendeu? (P1)

Através da análise de conteúdo, identificamos que apenas alguns alunos do curso de medicina conseguiram definir o que seria a ortotanásia.

A ortotanásia, pelo que eu sei é sobre uma morte boa. Basicamente isso que eu acho que é. A pessoa ter uma dignidade na morte. Você ter uma doença relativamente incurável e ter a opção de você morrer sem dor, você ter a escolha de realmente estar do lado dos familiares ou não, escolher o tratamento ou não (M6)

Embora os acadêmicos de medicina soubessem definir do que se tratava a ortotanásia, nenhum citou ou associou esta prática com cuidados paliativos, configurando-desconhecimento conceitual deste último termo.

Em nossa pesquisa, após a primeira pergunta disparadora, o que você sabe sobre a ortotanásia e constatando que os alunos pareciam confusos em relação à sua conceituação, os pesquisadores explicavam o significado desta prática, para que pudessem dar continuidade à entrevista.

Na segunda categoria identificada, a respeito de quem deveria estar envolvido no processo da ortotanásia, os alunos dos 3 cursos apontaram a família como importante personagem deste processo.

Eu acho que a opinião dos familiares deve sempre ser considerada, mas deve linkar com a opinião do corpo clínico... (M3)

A sua família e todos os profissionais: os médicos, os enfermeiros, os fisioterapeutas, os psicólogos (E9)

... em termos ideais, eu acho que seria um assunto que deveria ser mais discutido ainda em vida, com o próprio paciente [...] Os familiares mais próximos, aqueles que têm uma ligação mais próxima com o paciente envolvido (P2)

eu acho que primeiramente o paciente. Tem que respeitar a vontade dele, depois vem os familiares, depois vem os médicos e enfermeiros, ... nós 
ali não temos que tomar decisão nenhuma pelo paciente (P1)

A diferença se deu no fato de que enquanto para os alunos de medicina e enfermagem a participação da família deveria estar associada à decisão do corpo clínico, para os alunos de psicologia o paciente apareceu como o autor da decisão.

... o paciente tem o direito de escolha. Se ele estiver consciente ele tem o direito de escolha. $E$ pode haver um choque entre os dois [família e paciente]. Eu acho que ai entra o nosso papel como profissional para acolher e auxiliar nisso tudo (P3)

Nota-se que os alunos de psicologia não se inserem ativamente no processo, como os alunos de medicina e enfermagem, se colocando muito mais como um facilitador do momento, respeitando as escolhas da família e do paciente, do que como um personagem que contribuiria na tomada de decisão.

Ainda na segunda categoria, quem deveria estar envolvido no processo da ortotanásia, foi possível identificar que os graduandos de enfermagem e psicologia, evidenciaram o que caberia a cada profissional realizar durante esse processo de decisão.

... o principal papel [da enfermagem] é promover conforto aos familiares [...] conscientizar os familiares (E10)

Eu acho que primeiramente eu acolheria, para tentar compreender a visão que essa família, esse doente tem sobre a morte, sobre a perda, antes de começar a tomar qualquer atitude, porque senão eu ia estar impondo pontos de vistas e valores meus, pessoais que eu acho que não poderia nesse caso influenciar (P3)

Evidencia-se que os alunos dos cursos de enfermagem e psicologia consideram o acolhimento à família importante no processo de decisão pela ortotanásia, entretanto, ressalta-se que além do acolhimento, os acadêmicos de enfermagem trouxeram a importância da conscientização da família a respeito do que se iria fazer com o paciente. Esta diferença talvez tenha ocorrido por causa dos diferentes conhecimentos das áreas de atuação. Enquanto a enfermagem possui conhecimentos para explicar como se chega à constatação da condição da terminalidade do paciente, baseada em conhecimentos específicos e técnicos da área biológica, cabe aos alunos de psicologia acolher tanto os familiares, quanto o paciente neste difícil momento.

Em relação à terceira categoria, sentimentos perante as vivências de morte, evidenciou-se dificuldade para esta experiência no discurso dos estudantes dos cursos de medicina e enfermagem que já tinham passado por tal situação.
... uma coisa em mim que provoca um desconforto... (M3)

... foi difícil porque saber da vida da pessoa, que ela era uma pessoa ativa e aí não tinha mais jeito e só estavam esperando a morte mesmo [...] eu não reagi muito bem, eu saí chateada (E3)

Também foram encontrados alunos do curso de enfermagem e psicologia que não tinham vivenciado esta situação. Enquanto para os primeiros a experiência era considerada como difícil, por não se sentirem preparados, os alunos de psicologia não souberam precisar quais sentimentos poderiam emergir, por não terem vivenciado esta experiência, nem mesmo nas instituições de saúde em que realizavam estágios.

Eu acredito que eu não estaria pronta psicologicamente para o enfrentamento de uma morte. (E10)

... a gente não viveu essa realidade, então para a gente é bem que distante. (P1)

\section{Discussão}

Os resultados obtidos e evidenciados na constituição da primeira categoria "conhecimento sobre ortotanásia" mostraram que alguns alunos de medicina conseguiram definir o que seria ortotanásia, entretanto demonstraram insegurança ao falar sobre o tema. Além disso, em nenhum relato foi citado explicitamente o termo cuidado paliativo como parte do processo da ortotanásia. Válido ressaltar que os cuidados paliativos, bem como o respeito ao direito do paciente, se constituem como meio eficazes para prevenir a prática da distanásia $^{14}$, garantindo assim, uma qualidade de vida próxima a finitude e uma morte digna $a^{4,6,8}$.

A falta de familiarização de estudantes de medicina com os conceitos bioéticos relacionados à morte ocorre principalmente devido à baixa prioridade do tema na graduação ${ }^{15}$, o que acarretaria também no despreparo do discente no enfrentamento da morte ${ }^{15-18}$. Este despreparo pode levar a reações emocionais negativas ao lidar com o paciente terminal e seus familiares com consequente impacto no cuidar, podendo comprometer inclusive a saúde mental do estudante ${ }^{19}$. A falta de informação em relação aos conceitos bioéticos frente à terminalidade persiste também no exercício profissional do médico, que, por vezes, chega a omitir informações no prontuário temendo punições pelo código de ética médica ou código penal ${ }^{20}$.

Os alunos de enfermagem também relataram a pouca ênfase dada ao assunto e não sou- 
beram definir a ortotanásia. Este desconhecimento permanece até mesmo nos profissionais da enfermagem que atuam em unidades de terapia intensiva. Pesquisa ${ }^{2}$ realizada com estes profissionais identificou que dois terços destes não foram capazes de conceituar ortotanásia corretamente, o que poderia culminar no uso de procedimentos que causariam um prolongamento inútil do sofrimento.

Em relação aos alunos de psicologia, estes também afirmaram terem o tema ortotanásia abordado durante a graduação, porém mesmo assim não conseguiram defini-lo corretamente. Nossa pesquisa corrobora resultados encontrados em outros trabalhos ${ }^{9,21}$ que identificaram que os estudantes de psicologia não estão sendo preparados adequadamente para o confronto com a morte. Válido ressaltar que o conhecimento deste tema, ao contrário do que se pensa, não se aplica apenas à atuação em hospitais, pois situações de morte e perda ocorrem em todos os tipos de contextos, como o escolar, o clínico e, inclusive, o organizacional.

$\mathrm{Na}$ segunda categoria, "quem deveria se envolver no processo da ortotanásia", a família do paciente apareceu como personagem principal nos relatos dos acadêmicos dos 3 cursos. Ressalta-se, entretanto, que para a existência da relação saudável entre os "profissionais de saúde e a família de paciente" é necessário que ambas as partes consigam responder às demandas esperadas por cada uma. Neste contexto, os futuros profissionais de saúde afirmam considerar a opinião da família importante no processo da ortotanásia, em contrapartida, a família espera da equipe médica não só o cuidado ao doente, mas também que os profissionais da saúde os auxiliem para a decisão sobre a ortotanásia, através de informações, conscientizações e acolhimento ${ }^{3}$. Acontece, porém, como mostram nossos resultados, que estes profissionais frequentemente demonstram dúvidas éticas e legais quanto à ortotanásia, não se configurando, portanto, como capacitados para responder às demandas da família neste processo ${ }^{16}$. Isto nos faz pensar que a formação destes profissionais de saúde deve compreender também o desenvolvimento de competências com enfoque nas relações interpessoais para melhor comunicação com pacientes e familiares ${ }^{8,18}$. Uma boa comunicação entre médicos e familiares a respeito da situação terminal do paciente pode facilitar a aceitação da morte, podendo evitar uma sobrecarga de estresse ${ }^{22}$.

Ainda em relação ao papel dos profissionais da saúde no processo da ortotanásia, os futuros enfermeiros evidenciaram o ato de confortar o paciente e principalmente a família neste momento de decisão. Frente à inevitabilidade da morte, o cuidador familiar sofre alterações emocionais, desgaste físico e precisa do apoio da equipe paliativista $^{23}$. A postura de acolhimento à família também foi encontrado em outros estudos ${ }^{2,7,24}$ que identificaram esta atitude como parte de um tratamento com dignidade e qualidade.

Os estudantes de psicologia tiveram um discurso semelhante no que diz respeito ao papel desenvolvido no processo da ortotanásia. Para estes graduandos, a função do psicólogo é acolher o paciente e, em alguns casos, a atenção aos familiares foi também citada. Esta atuação auxilia o doente a ter uma morte digna apoiando, principalmente, os familiares no estabelecimento de uma comunicação franca no momento da despedida $^{25}$.

Quanto à terceira categoria, os sentimentos vivenciados frente à temática da morte, os resultados da pesquisa revelaram que os estudantes de medicina e enfermagem têm dificuldades em lidar com a morte e não se sentem preparados para seu enfrentamento. Estudo realizado ${ }^{26} \mathrm{com}$ os profissionais médicos e da área da enfermagem mostrou que uma das razões para isso talvez seja a falta de espaço para a expressão de seus sentimentos frente à morte e à escassez de recursos teóricos que sentem possuir. Também os estudantes de medicina não se sentem apoiados quando ocorre a morte de seu paciente e desta maneira não aprendem a se relacionar com suas próprias emoções ${ }^{19}$. Já os enfermeiros recém-formados mostram consistentemente grande medo em relação à morte e apresentam atitudes negativas frente ao cuidar do doente terminal ${ }^{27}$. Estes trabalhos identificaram que o preparo para trabalhar com pacientes terminais deve começar nos cursos de graduação para que o profissional de saúde incorpore esta habilidade em sua formação e seja capaz de ver o paciente terminal como um ser humano que necessita de sua ajuda nesta etapa final de sua vida.

Tais dificuldades encontradas por estudantes de medicina e enfermagem no enfrentamento da morte nos faz pensar que para estes acadêmicos esta vivência é uma situação quase sempre dolorosa e permeada de intenso sofrimento, podendo resultar até mesmo em depressão ${ }^{18}$ uma vez que frente à terminalidade da vida estes profissionais apresentam ansiedade, estresse e insegurança ${ }^{28}$.

Também nos chama a atenção a falta de vivência destas experiências entre os estudantes de psicologia, dificultando o relato dos possíveis 
sentimentos frente à condição de terminalidade do paciente, porém é preciso se considerar que nem sempre os estágios são realizados em hospitais com serviços estruturados de cuidados paliativos.

\section{Considerações finais}

A maioria dos acadêmicos entrevistados não soube definir de forma correta o que seria ortotanásia, embora o tema tivesse sido contemplado na graduação. Quando orientados pelos entrevistadores a respeito do que se tratava, muitos se lembraram do tema e conseguiram refletir a respeito. Esta constatação nos permite inferir que para muitos dos acadêmicos o conhecimento teórico esteve dissociado da prática e vice-versa. No que se refere ao processo da ortotanásia, esta dissociação pode implicar no sofrimento do profissional por acreditar estar praticando algo ilegal e, por outro lado, pode também promover o sofrimento inútil do paciente em condição terminal.

Lidar com a terminalidade implica na aceitação da morte e em uma visão do paciente que vai além da doença a ser combatida a todo custo, exigindo intervenções que enfoquem o doente em toda a sua integralidade e garantindo uma maior qualidade no processo de morrer. A incapacidade de lidar com a morte intensificam a angústia e a dor dos profissionais da saúde, que além de enfrentarem a sua própria finitude, vivenciam as emoções experimentadas pelo paciente e seus familiares,

A discussão sobre os cuidados paliativos deveria estar mais presente nos nossos hospitais e ser considerada como uma opção de tratamento na fase final de vida sem que isto fosse visto como uma derrota frente à morte inevitável. É necessário ampliar-se a discussão sobre o modelo médico ainda vigente em nossos hospitais que privilegia o combate à doença a todo custo, complementando uma formação dos profissionais da saúde focada na tecnicidade.

Dentro desse contexto, torna-se urgente a reformulação das grades curriculares dos cursos da área da saúde com a inclusão de disciplinas que promovam a reflexão sobre as questões da morte e do morrer. Somente através desta formação integral, estes profissionais compreenderão o homem além da doença, sendo capazes de oferecer ao paciente uma morte com qualidade em um atendimento humanizado e a seus familiares um conforto emocional na fase final da vida.

\section{Colaboradores}

LRG Santos, MP Menezes e SMO Gradvohl participaram igualmente de todas as etapas da elaboração do artigo. SMO Gradvohl foi idealizadora do trabalho e responsável pela orientação geral do estudo.

\section{Agradecimentos}

Ao Núcleo de Pesquisa Acadêmica da Universidade São Francisco pelo incentivo à iniciação científica dos alunos LRG Santos (bolsista PROBAIC/USF) e MP Menezes, sob a orientação da Prof MS. SMO Gradvohl. 


\section{Referências}

1. Conselho Federal de Medicina. Resolução 1.805/ 2006. Diário Oficial da União 2006; 28 nov.

2. Biondo CA, Silva MJP, Dal Secco LM. Distanásia, eutanásia e ortotanásia: percepções dos enfermeiros de unidades de terapia intensiva e implicações na assistência. Rev Lat Am Enfermagem 2006; 17(5): 613-619.

3. Santos MFG, Bassit DP. Terminalidade da vida em terapia intensiva: posicionamento dos familiares sobre ortotanásia. Rev. bras. ter. intensiva 2011; 23(4):448-454.

4. Combinato DS, Queiroz MDS. Morte: uma visão psicossocial. Estud psicol (Natal) 2006; 11(2):209216

5. Floriani CA, Schramm FR. Cuidados paliativos: interfaces, conflitos e necessidades. Cien Saude Colet 2008; 13(Supl. 2):2123-2132.

6. Chaves JHB, Mendonça VLG, Pessini L, Rego G, Nunes R. Cuidados paliativos na prática médica: contexto bioético. Rev dor 2011; 12(3):250-255.

7. Monteiro FF, Oliveira M, Vall J. A importância dos cuidados paliativos na enfermagem. Rev dor 2010; 11(3):242-248.

8. Medeiros LA, Lustosa MA. A difícil tarefa de falar sobre morte no hospital. Rev. SBPH 2011; 14(2):203227.

9. Lima VR, Buys R. Educação para a morte na formação de profissionais de Saúde. Arq Bras Psicol 2008; 60(3):52-63.

10. Fontanella, BJB, Ricas J, Turato ER. Amostragem por saturação em pesquisas qualitativas em saúde: contribuições teóricas. Cad Saude Publica 2008; 24(1):17-27.

11. Bardin L. Análise de conteúdo. Lisboa: Edições 70; 2006.

12. Campos CJG. Método de análise de conteúdo: ferramenta para a análise de dados qualitativos no campo da saúde. Rev Bras Enferm. 2004; 57(5):611-614.

13. Minayo MCS. O desafio do conhecimento: pesquisa qualitativa em saúde. 8a Edição. São Paulo, Rio de Janeiro: Hucitec, Abrasco; 2004.

14. Menezes MB, Selli L, Alves JS. Distanásia: percepção dos profissionais da enfermagem. Rev Lat Am Enfermagem 2009; 17(4):443-448.

15. Pinheiro A, Nakazone MA, Leal FS, Pinhel MAS, Souza DRSS, Cipullo JP. Conhecimento de estudantes de medicina sobre tomada de decisão no fim da vida. Rev Bras Educ Med 2011; 35(2):171-176.

16. Marta GN, Marta NM, Filho AA, Job JRPP. O estudante de Medicina e o médico recém-formado frente à morte e ao morrer. Rev Bras Educ Med 2009; 33(3):416-427.

17. Bifulco VA, Iochida LC. A formação na graduação dos profissionais de saúde e a educação para o cuidado de pacientes fora de recursos terapêuticos de cura. Rev Bras Educ Med 2009; 33(1):91-100.
18. Sadala MLA, Silva MP. Cuidar de pacientes em fase terminal: a experiência de alunos de medicina. Interface (Botucatu) 2008; 12(24):7-21.

19. Anderson WG, Williams JE, Bost, JE, Barnard D. Exposure to death is associated with positive attitudes and higher knowledge about end-of-life care in graduating medical students. J Palliat Med 2008; 11(9):1227-1233.

20. Gaudencio D, Messeder O. Dilemas sobre o fimda-vida: informações sobre a prática médica nas UTIs. Cien Saude Colet 2011; 16(Supl. 1):813-820.

21. Junqueira MHR, Kovács MJ. Alunos de Psicologia e a Educação para a Morte. Psicol., Ciênc. Prof. (Impr) 2008; 28(3):506-519.

22. Tam A, Manca D. Finding common ground to achieve a "good death": family physicians working with substitute decision-makers of dying patients. A qualitative grounded theory study. BMC Fam Pract. 2013; 14(1):1-11.

23. Fratezi FR, Gutierrez BAO. Cuidador familiar do idoso em cuidados paliativos: o processo de morrer no domicílio. Cien Saude Colet 2011; 16(7):32413248.

24. Toffoletto MC, Zanei SSV, Hora EC, Nogueira GP, Miyadahira AMK, Kimura M, Padilha KG. A distanásia como geradora de dilemas éticos nas unidades de terapia intensiva: considerações sobre a participação dos enfermeiros. Acta Paul Enferm 2005; 18(3):307-312.

25. Pereira LL, Dias ACG. O Familiar cuidador do paciente terminal: o processo de despedida no contexto hospitalar. Psico. 2007; 38(1):55-65.

26. Quintana AM, Kegler P, Santos MS, Lima LD. Sentimentos percepções da equipe de saúde frente ao paciente terminal. Paidéia 2006; 16(35):415-425.

27. Peters L, Cant R, Payne S, O'Connor M, McDermott F, Hood K, Morphet J, Shimoinaba K. How death anxiety impacts nurses' caring for patients at the end of life: a review of literature. Open Nurs J. 2013; 7:14-21.

28. Takahashi CB, Contrin LM, Beccaria LM, Goudinho MV, Pereira RAM. Morte: percepção e sentimentos de acadêmicos de enfermagem. Arq Ciênc Saúde 2008; 15(3):132-138.

Artigo apresentado em 30/04/2013

Aprovado em 22/05/2013

Versão final apresentada em 18/06/2013 
